\title{
Phenanthroimidazole-based Covalent Organic Frameworks with En- hanced Activity for the Photocatalytic Hydrogen Evolution Reaction
}

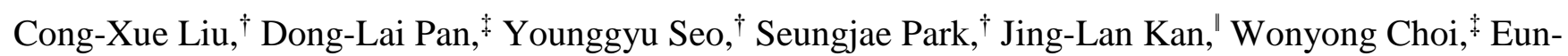 \\ sung Lee*广 \\ $\dagger$ Department of Chemistry, Pohang University of Science and Technology, Pohang, 37673, Republic of Korea \\ $¥$ Division of Environmental Science and Engineering, Pohang University of Science and Technology, Pohang, 37673, Republic of Korea \\ ' College of Chemistry, Chemical Engineering and Materials Science, Collaborative Innovation Center of Functionalized Probes for Chem- \\ ical Imaging in Universities of Shandong, Key Laboratory of Molecular and Nano Probes, Ministry of Education, Shandong Normal Uni- \\ versity, Jinan 250014, P. R. China
}

\begin{abstract}
The rational design of organic semiconductors based on crystalline covalent organic frameworks (COFs) as efficient photocatalysts is highly desirable. In this study, the first example of phenanthroimidazole-based COFs is reported: PImCOF1 with an imine linkage and PIm-COF2 with a $\beta$-ketoenamine-linkage. Both $\mathrm{COF}$ materials showed substantial optical properties. The average hydrogen evolution rate was $7417.5 \mu \mathrm{molg}^{-1} \mathrm{~h}^{-1}$ for PIm-COF2, which was 20 times higher than that of PIm-COF1 $\left(358.5 \mu \mathrm{molg}^{-1} \mathrm{~h}^{-1}\right)$. This can be attributed to the strong donor-acceptor effect of PIm-COF2 and the continuous separation and transfer of the photoexcited electron-hole pair from the phenanthro[9,10-d]imidazole moiety.
\end{abstract}

KEYWORDS covalent-organic frameworks, photocatalytic hydrogen evolution, phenanthro[9,10-d]imidazole derivatives

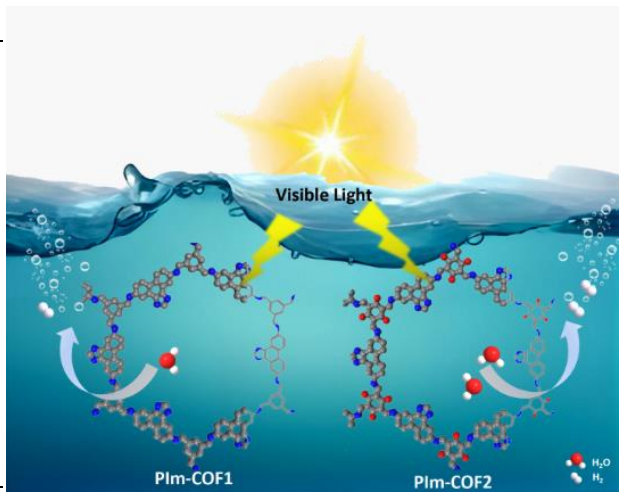

\section{INTRODUCTION}

Covalent organic frameworks (COFs) are an emerging class of organic semiconductor materials composed of atomically organized organic subunits connected by strong covalent bonds. The photocatalytic potential of COFs has already been reported. ${ }^{1,2}$ The highly crystalline nature of COFs and long-range order in the material not only benefits the light-harvesting capacity and transfer of photogenerated electrons to the surface but also prevents electron-hole pair combination. ${ }^{3,4}$ The tunability of building blocks allows for linkage diversity in COFs, such as the $\beta$ ketoenamine linkage, ${ }^{5,6}$ triazine linkage, ${ }^{7,8}$ and olefin linkage, ${ }^{9,10}$ which also contributes to the development of COF organic semiconductors with excellent optical and electronic properties. COFs have exhibited a high performance as heterogeneous organic photocatalysts, owing to their high porosity as well as good chemical and thermal stability. ${ }^{11-13}$ Three key factors are required for COFs to qualify as photocatalysts; (i) a broad light absorption range, (ii) the separation and migration of photoexcited electron-hole pairs, and (iii) an appropriate oxidation-reduction potential. ${ }^{14-16}$ Among them, the generation and migration rate of photogenerated electron-hole pairs determines the progress of the photocatalytic reaction. Therefore, it is essential to rationally design and synthesize COFs with a high capacity for photogenerated electron-hole separation and migration for application in photocatalysis.

Phenanthroimidazole derivatives exhibit a rigid-planar-conjugate structure and ambipolar characteristics owing to the bonding structures of the two nitrogen atoms of the imidazole ring. ${ }^{17,} 18$ These derivatives have been widely employed as blue light-emitting materials based on their high carrier mobilities and conductivities, high triplet energies, and high fluorescent efficiencies. ${ }^{19-21}$ Therefore, the phenanthroimidazole unit is a good candidate for the fabrication of COFs. However, no welldefined COF synthetic route from phenanthroimidazole derivaties has been reported to date. Herein, we report the first example of phenanthroimidazole-based COFs applied as highly efficient photocatalysts in the hydrogen evolution reaction (HER). Phenanthro[9,10-d]imidazole-5,10-diamine was synthesized as a new building block and was subjected to condensation with 1,3,5-benzenetricarboxaldehyde and 2,4,6-triformylphloroglucinol to yield PIm-COF1 and PIm-COF2, respectively, as potential photocatalysts.

\section{RESULTS AND DISCUSSION}

PIm-COF1 and PIm-COF2 were synthesized via the condensation of 1H-phenanthro[9,10-d] imidazole-5,10-diamine (PIDA, 1) with different aldehyde building blocks, such as 1,3,5-benzenetricarboxaldehyde (BTA, 2) and 2,4,6-triformylphloroglucinol (TP, 3), under solvothermal conditions (Figure 1a and Scheme S1 ESI $\dagger$ ). PXRD measurements were performed for all samples to verify the successful formation of PIm-COF1 and PIm-COF2. As shown in Figure 1b, PImCOFs exhibit a typical two-dimensional (2D) layered hexagonal network structure. The PXRD patterns of PIm-COF1 exhibited an intense peak at $3.5^{\circ}$ and three minor peaks at 6.9, 9.0, and $25.5^{\circ}$, which correspond to the (100), (200), (210), and (001) 
(a)

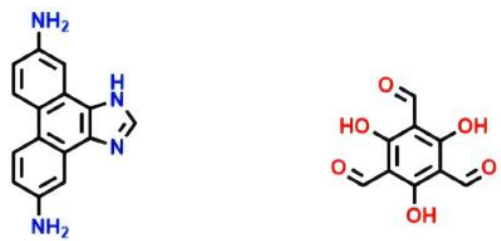

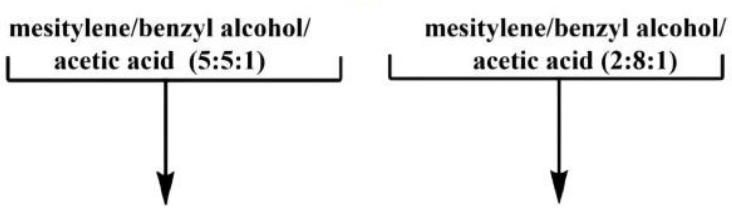

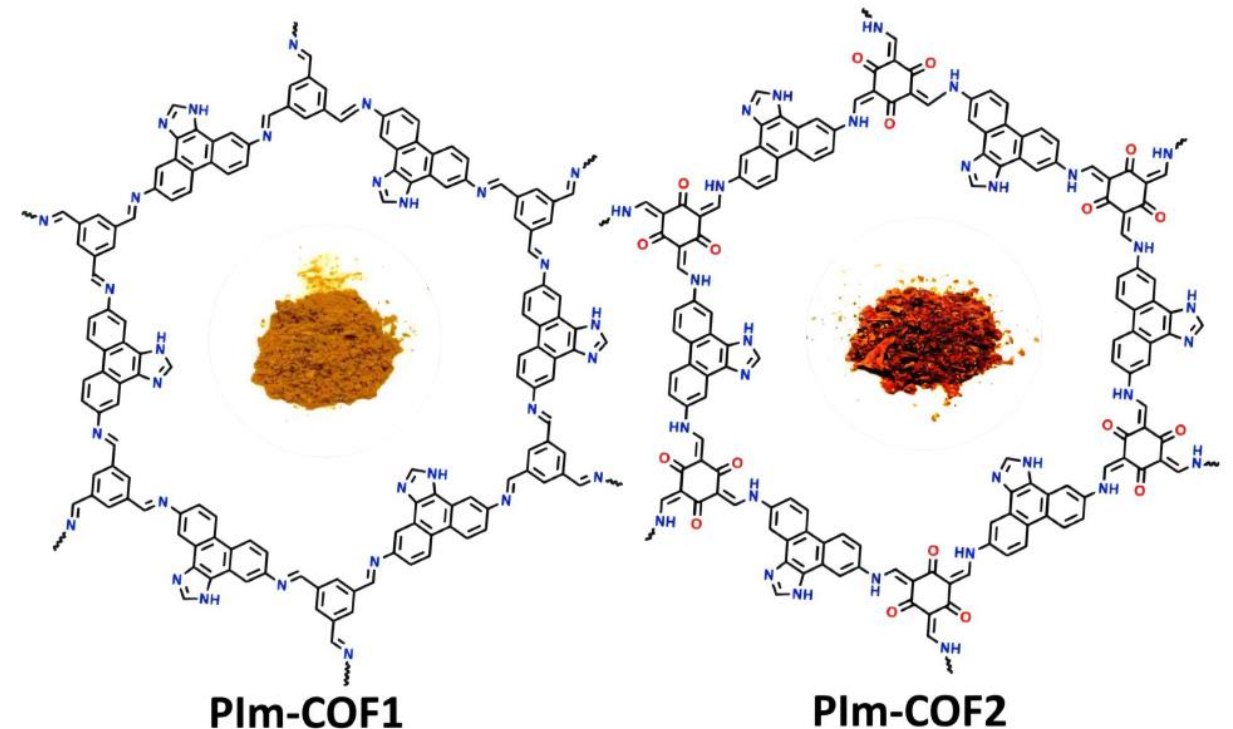

(b)
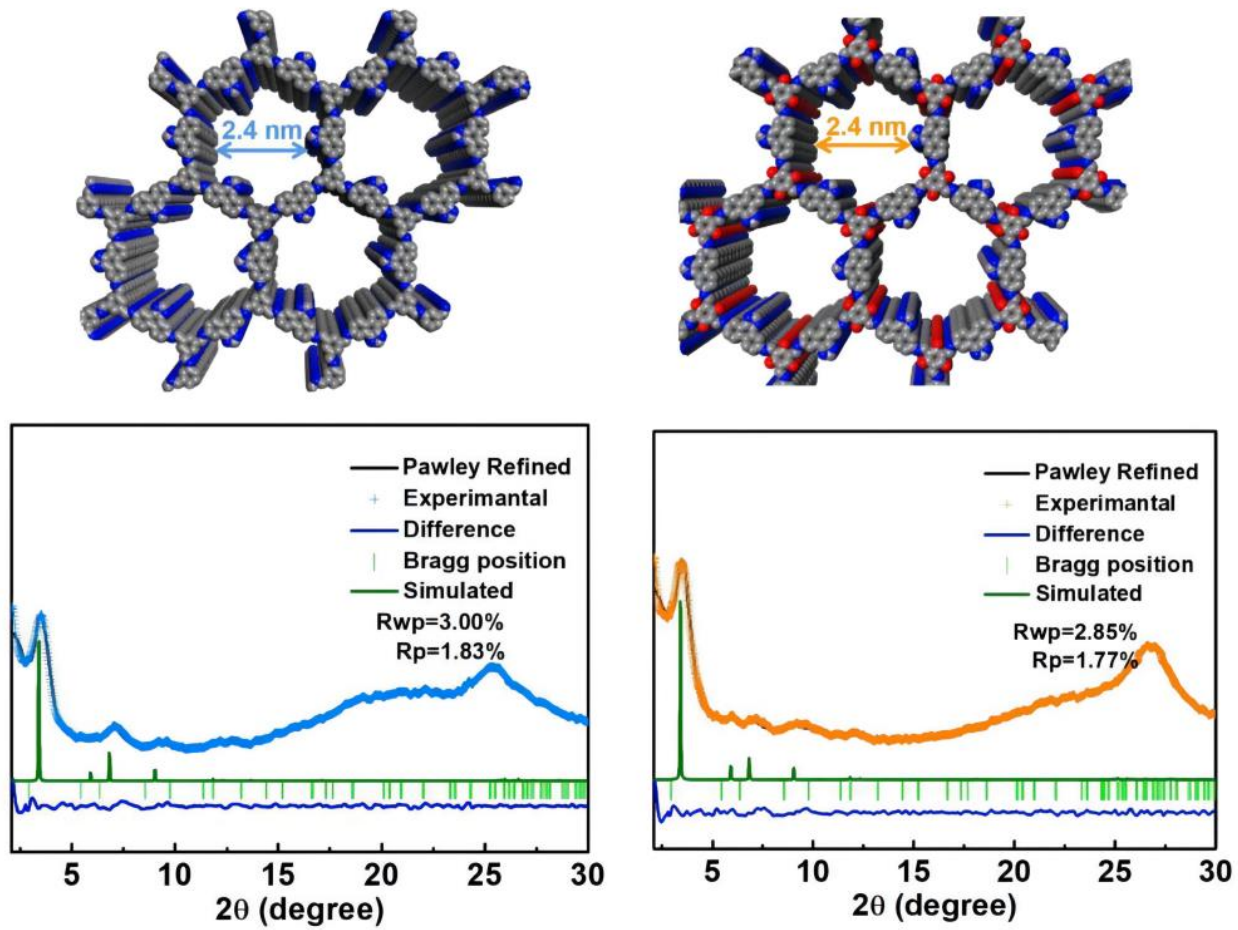

Figure 1. (a) Schematic illustration for the synthesis of PIm-COFs. (b) Experimental, Pawley-refined, and AA model simulated powder X-ray diffraction (PXRD) patterns of PIm-COF1 (right) and PIm-COF2 (left) (with side views of the ideal eclipsed structures). 
reflections, respectively. The PXRD pattern of PIm-COF2 showed a major diffraction peak at $3.4^{\circ}$ and three minor peaks at $5.9,6.9,9.0$, and $26.0^{\circ}$, which correspond to the (100), (110) (200), (210), and (001) reflections, respectively. The experimental PXRD patterns corresponded well with the patterns simulated using the eclipsed AA layer stacking model (Figure 1b;

(a)

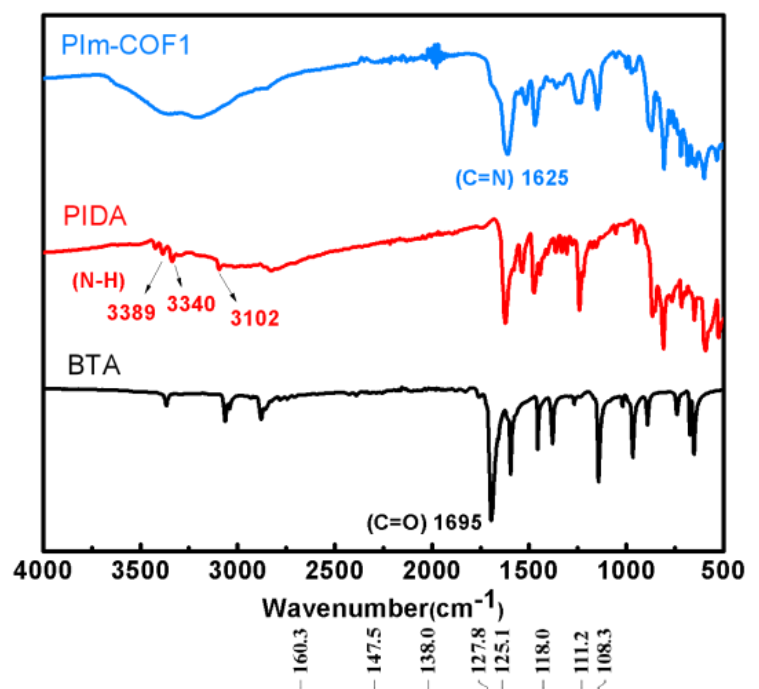

(c)

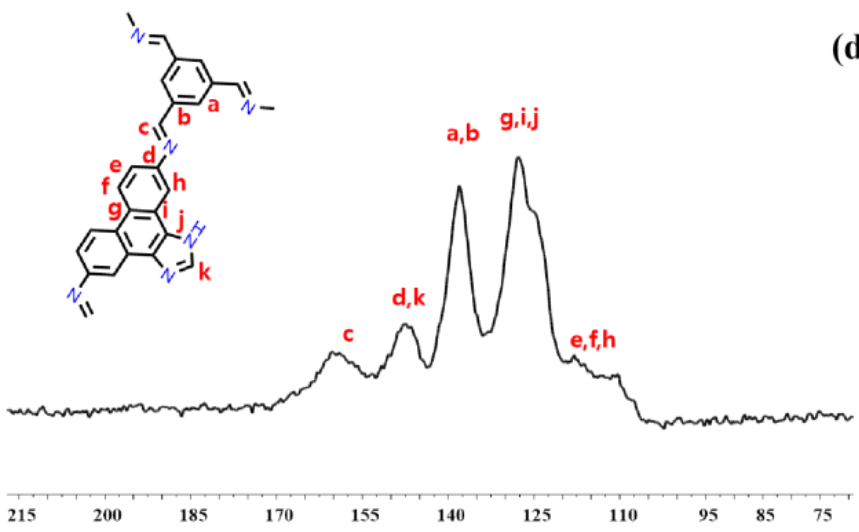

Figure S1). The lattice parameters of PIm-COFs were extracted using Pawley refinement with the P3 hexagonal space group, and low residual values and acceptable profile differences were observed (Figure 1b; Table S1 and S2).

(b)

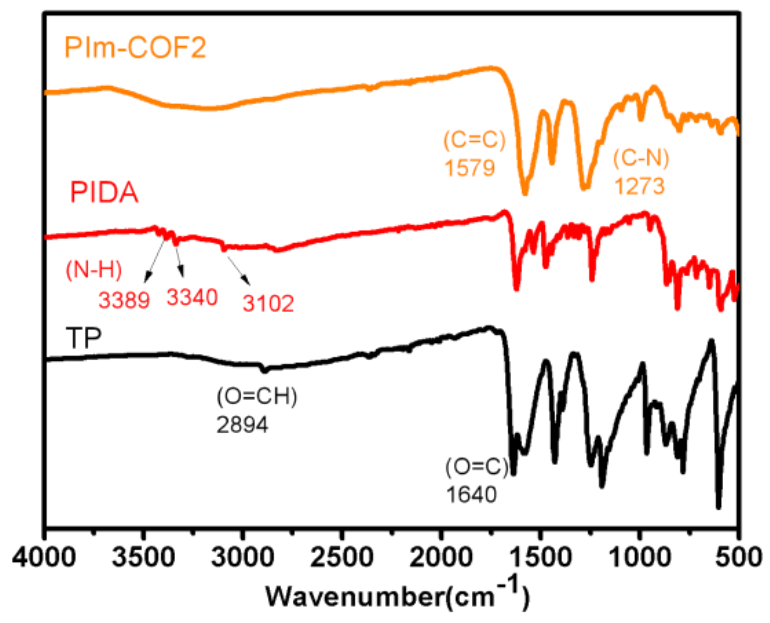

(d)

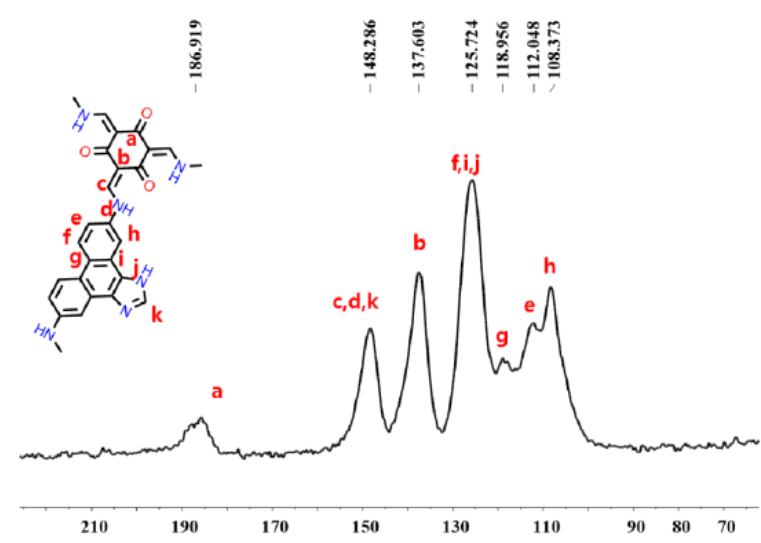

Figure 2. FT-IR spectra of (a) PIm-COF1 and (b) PIm-COF2, and ${ }^{13} \mathrm{C}$ CP/MAS NMR spectra of (c) PIm-COF1 and (d) PIm-COF2.

Fourier transform infrared (FT-IR) and ${ }^{13} \mathrm{C}$ cross-polarization magic angle spinning (CP-MAS) nuclear magnetic resonance (NMR) spectroscopies were performed to examine the chemical composition of PIm-COF1 and PIm-COF2 (as shown in Figure 2). The FT-IR spectra of the two samples indicated the complete conversion of the starting materials based on the disappearance of the $\mathrm{N}-\mathrm{H}$ stretching vibrational peaks of PIDA (3102, 3340, and $\left.3389 \mathrm{~cm}^{-1}\right)$. The disappearance of the $\mathrm{C}=\mathrm{O}$ stretching vibrational peak of BTA $\left(1695 \mathrm{~cm}^{-1}\right)$ and the appearance of the $\mathrm{C}=\mathrm{N}$ stretching vibration for PIm-COF1 (Figure 2a) at $1625 \mathrm{~cm}^{-1}$ confirmed the formation of the imine linkage. The characteristic vibration of the $\mathrm{C}=\mathrm{O}$ stretching band of TP $(1640$ $\mathrm{cm}^{-1}$ ) disappeared and a strong peak at $1579 \mathrm{~cm}^{-1}$ was observed for PIm-COF2 (Figure 2b), which may be attributed to the $\mathrm{C}=\mathrm{C}$ stretching vibration of the keto form. Additionally, the absence of hydroxyl $(-\mathrm{OH})$ and imine $(\mathrm{C}=\mathrm{N})$ stretching peaks confirmed the existence of the keto form instead of the enol form. Solidstate ${ }^{13} \mathrm{C}$ NMR spectroscopy also confirms that the condensation reaction occurred to form the PIm-COF1 structure (Figure 2c), as the spectrum exhibits a characteristic peak at $160.3 \mathrm{ppm}$, which corresponds to the carbon atom of the $\mathrm{C}=\mathrm{N}$ bond. A signal at 186.9 ppm was observed for the PIm-COF2 structure, which may be attributed to the carbonyl carbon $(\mathrm{C}=\mathrm{O})$ of the keto form (Figure 2d). The FT-IR and XRD results, therefore, confirmed that PIm-COF1 and PIm-COF2 formation was successfully achieved.

$\mathrm{N}_{2}$ adsorption-desorption measurements at $77 \mathrm{~K}$ were performed to elucidate the porosity of PIm-COFs (Figure S2a). Both PIm-COF1 and PIm-COF2 displayed a type-I isotherm, which indicates that the $\mathrm{COF}$ materials possess a microporous structure. The Brunauer-Emmett-Teller (BET) surface area was 1004 and $950 \mathrm{~m}^{2} \mathrm{~g}^{-1}$ for PIm-COF1 and PIm-COF2, respectively. PIm-COFs had a relatively uniform pore size distribution with an average pore size of $2.2 \mathrm{~nm}$ according to the nonlocal density functional theory (DFT) calculation method (Figure S2b). Both PIm-COFs exhibited good $\mathrm{CO}_{2}$ uptake behavior in the isothermic adsorption studies performed at $273 \mathrm{~K}$ (Figure S2c). However, the $\mathrm{CO}_{2}$ adsorption capacity of PIm- 
COF2 was $64 \mathrm{~cm}^{3} \mathrm{~g}^{-1}$, which was higher than that of PImCOF1 $\left(49 \mathrm{~cm}^{3} \mathrm{~g}^{-1}\right)$. This may be attributed to the strong affinity between the structure after keto-enol tautomerization and $\mathrm{CO}_{2}$ molecules. $^{22,23}$ The thermal stability of PIm-COFs was also analyzed by thermogravimetric analysis (TGA), and the PImCOFs were observed to be thermally stable up to $623 \mathrm{~K}$ (Figure S3). To evaluate the chemical stability, activated PIm-COFs samples were immersed in $0.1 \mathrm{M}$ ascorbic acid, $3 \mathrm{M}$ aqueous $\mathrm{HCl}$, and $3 \mathrm{M} \mathrm{NaOH}$ solutions and DMSO at $298 \mathrm{~K}$ for one week. Notably, PIm-COF1 samples exhibited different degrees of loss in crystallinity, whereas PIm-COF2 retained strong diffraction peaks (that is, crystallinity) (Figure S4).

(a)

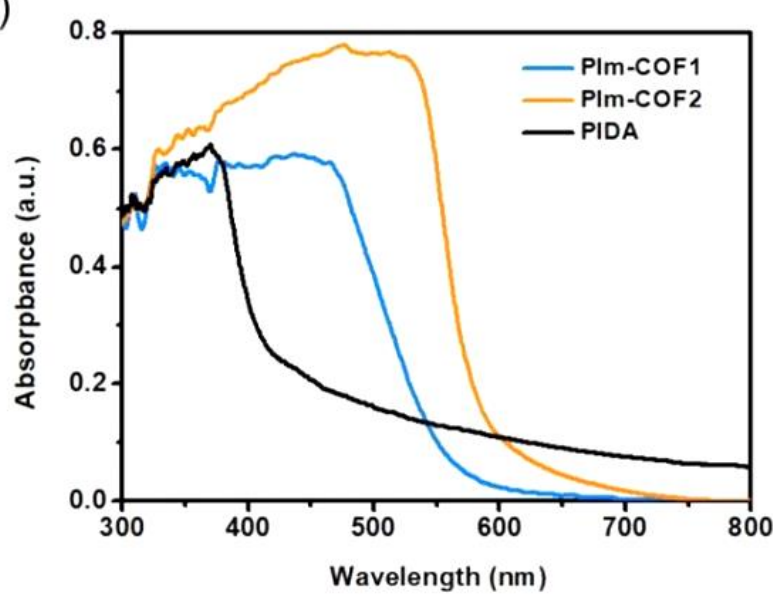

(c)

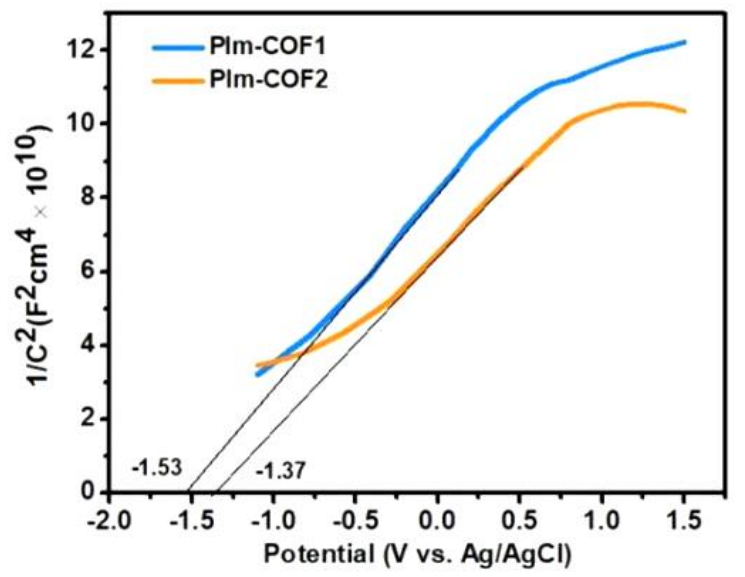

The optical band gap energy of PIm-COF1 and PIm-COF2 were 2.34 and $2.13 \mathrm{eV}$, respectively, which was obtained from the Tauc function $(\alpha h v)^{2}$ that is related to the incident photon energy, as shown in Figure 3b. Notably, the UV-vis spectra of PIm-COF1 and PIm-COF2 occupied a broader region compared with that of the secondary unit PIDA. PIm-COF2 exhibited a broader light absorption region compared to PIm-COF1, which may be ascribed to the enhanced D-A structure with a stronger conjugation effect between the $\beta$-ketoenamine linkage and PIDA ligand. ${ }^{24-26} \mathrm{MS}$ measurements were performed to determine the semiconductor type and flat band positions of PImCOFs (Figure 3c). The positive slopes observed for both PIm-

(b)

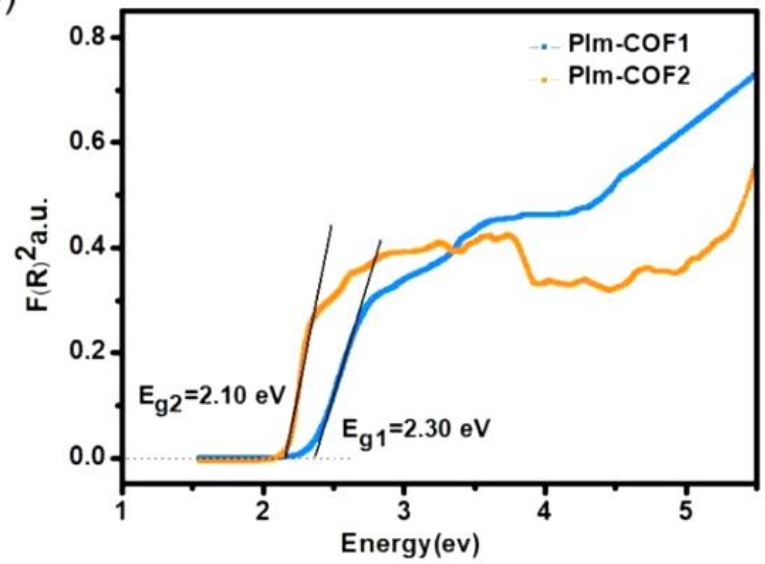

(d)

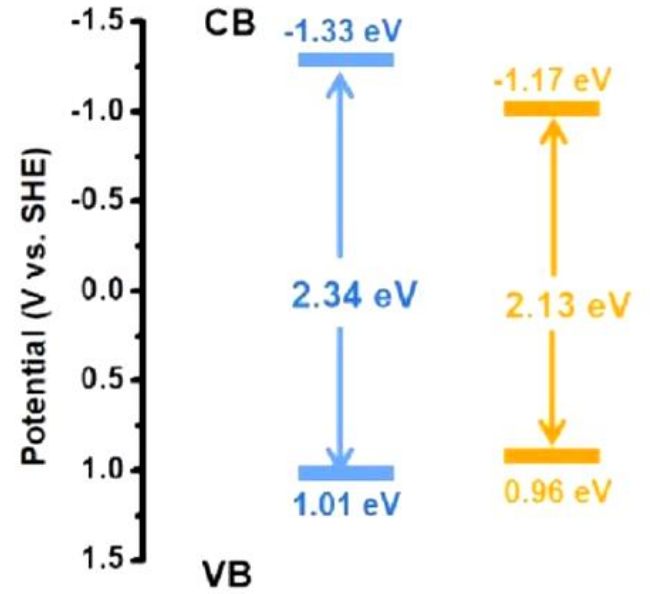

Figure 3. (a) UV-vis DSR spectra of PIm-COF1 (blue curve), PIm-COF2 (orange curve), and ligand PIDA (black curve). (b) Tauc plot transformed reflectance spectra. (c) MS plot for PIm-COF1 (blue curve) and PIm-COF2 (orange curve). (d) Energy levels of PIm-COFs.

The morphology of PIm-COFs was analyzed using scanning electron microscopy (SEM), which exhibited the homogeneous rod-like and microsphere-like crystallites of PIm-COF1 and PIm-COF2, respectively. (Figure S5). The uniform texture of PIm-COFs was further confirmed by SEM-EDX mapping, which showed a homogeneous distribution of $\mathrm{C}, \mathrm{N}$, and $\mathrm{O}$ elements in the COF matrix. Moreover, the morphologies of PImCOFs were analyzed by high-resolution transmission electron microscopy (HR-TEM), and the results matched well with the SEM findings (Figure S6).

The optical absorption properties of PIm-COFs were measured using Ultraviolet-visible diffuse reflectance (UV-vis DSR) spectroscopy (Figure 3a), which indicated that PIm-COFs samples possessed band structures sufficient to absorb visible light.
COF1 and PIm-COF2 indicated an n-type semiconducting nature. The calculated conduction-band positions were -1.33 and -1.17 eV for PIm-COF1 and PIm-COF2, respectively. Combined with the bandgap determined from UV-vis DSR data, the valence-band position was determined as 1.01 and $0.96 \mathrm{eV}$ for PIm-COF1 and PIm-COF2, respectively (Figure 3d).

The photoelectrochemical properties of the PIm-COFs were evaluated by Electrochemical impedance spectroscopy (EIS) and transient photocurrent measurements. From Figure 4a, Nyquist curves show that the semicircular radius of PIm-COF2 is smaller than that of PIm-COF1, indicating that the PImCOF2 has a lower charge transfer resistance and more rapid transfer of the photoinduced electrons than those of PIm-COF1. This result was further confirmed by the photocurrent measurements (Figure 4b). As expected, the intensity of the transient 
photocurrent response of PIm-COF2 was higher than that of PIm-COF1. Moreover, the photoluminescence (PL) spectrum of PIm-COF2 showed an emission peak at $620 \mathrm{~nm}$ with a very low intensity compared to that of PIm-COF1 observed at $588 \mathrm{~nm}$ (Figure 4c). experiments for up to $28 \mathrm{~h}$ under visible-light irradiation. PXRD patterns indicated that PIm-COF2 maintained its structural integrity even after 7 cycles (Figure $4 \mathrm{f}$ and S8).

The excellent photocatalytic activity of PIm-COF2 may be attributed to (i) high carrier mobilities, conductivities, and visi- (a)

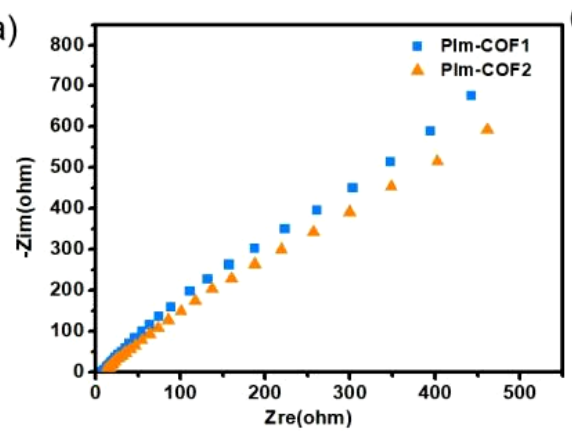

(d)

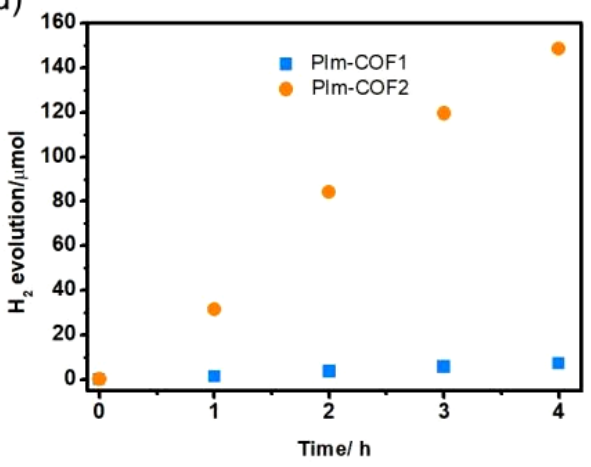

(b)

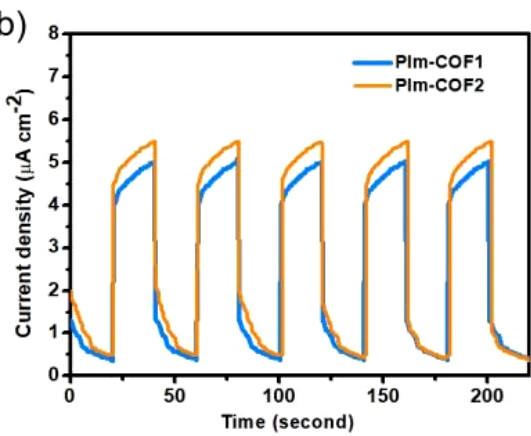

(e)

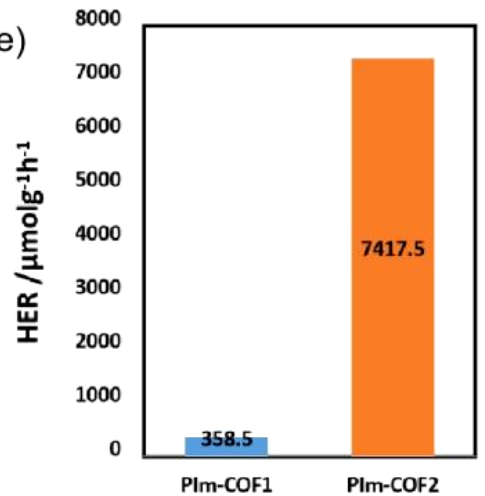

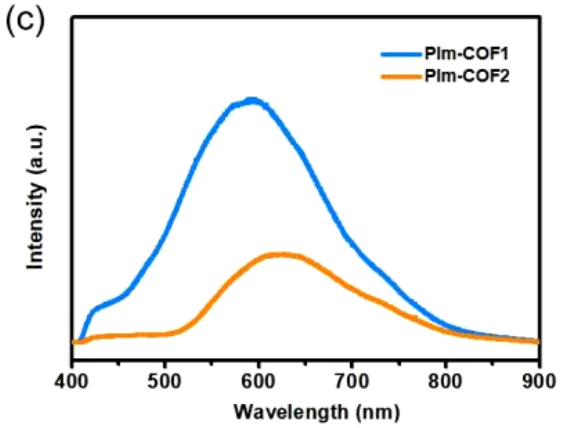

(f)

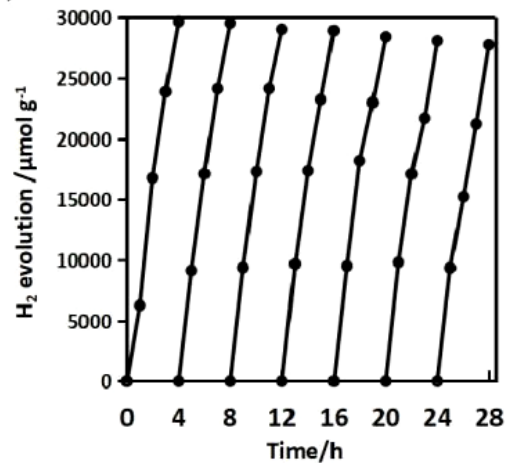

Figure 4.EIS Nyquist plots of PIm-COF1 (blue curve) and PIm-COF2 (orange curve); (b) transient photocurrent response of PIm-COF1 (blue curve) and PIm-COF2 (orange curve); (c) PL intensity of PIm-COFs; (d) $\mathrm{H}_{2}$ evolution of PIm-COFs monitored over 4 h; (e) HER

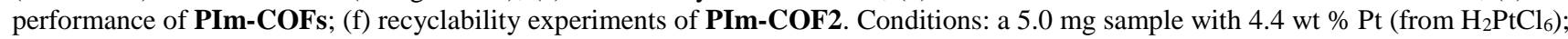
$0.1 \mathrm{M}$ ascorbic acid in $25.0 \mathrm{~mL} \mathrm{H}_{2} \mathrm{O}$; under irradiation of $\lambda \geq 420 \mathrm{~nm}$.

A broad visible light absorption range, suitable band positions, and a high separation efficiency of electron-hole pairs enable the application of PIm-COFs as photocatalysts in the HER. Their photocatalytic HER activity was evaluated in an aqueous solution with the irradiation of visible light $(\lambda \geq 420 \mathrm{~nm})$. Ascorbic acid was used as a sacrificial agent, and in situ photodeposited $\mathrm{Pt}$ nanoparticles (from $\mathrm{H}_{2} \mathrm{PtCl}_{6}$ ) served as cocatalysts. The average rate of HER was $7417.5 \mu \mathrm{molg}^{-1} \mathrm{~h}^{-1}$ for PIm-COF2, which was 20 times higher than that of PIm-COF1 (358.5 $\mu \mathrm{molg}^{-1} \mathrm{~h}^{-1}$ ) under optimal reaction conditions (Figures $4 \mathrm{~d}, 4 \mathrm{e}$, and S7). The photocatalytic activity of these PIm-COFs was also evaluated without the Pt cocatalyst, and PIm-COF2 was found to retain an HER reactivity of $84.6 \mu \mathrm{molg}^{-1} \mathrm{~h}^{-1}$ (Figure S7). In the absence of a catalyst in the reaction system, no $\mathrm{H}_{2}$ was generated. These findings further support the excellent optical properties and photocatalytic activities of newly synthesized $\beta$ ketoenamine linked PIm-COF2.

The apparent quantum efficiency (AQE) was determined to evaluate the photocatalytic activity of the PIm-COF samples (See Supporting Information). Although an AQE of $0.12 \%$ was determined for PIm-COF1, the AQE of PIm-COF2 could reach up to $2.52 \%$, which is among the highest efficienies reported to date compared to other $\beta$-ketoenamine linked COFs used as HER photocatalysts (Table S3). Apart from its excellent photocatalytic performance, PIm-COF2 exhibited high photocatalytic stability that was determined by performing cycling ble light adsorption capacity, which were enhanced by the phenanthro[9,10-d]imidazole derivative, (ii) the strong donor-acceptor effect between the $1 \mathrm{H}$-phenanthro[9,10-d] imidazole moiety and keto-form building blocks transformed by enol-keto tautomerism, and (iii) the 2D extended crystalline porous structure with improved light absorption regions, charge transfer, and interactions with aqueous solutions.

\section{CONCLUSION}

In summary, a new $1 \mathrm{H}$-phenanthro[9,10-d] imidazole-5,10-diamine derivative was successfully incorporated into a $\mathrm{COF}$ framework to form 2D PIm-COFs. The H-phenanthro[9,10-d] imidazole moiety imparted PIm-COFs with excellent optical properties. Significantly, $\beta$-ketoenamine linked PIm-COF2 showed an enhanced donor-acceptor effect that resulted in a broadened visible light absorption region, a narrowed optical band gap, and an accelerated charge separation and transfer. These properties resulted in a substantial photocatalytic performance between PIm-COFs in the HER.

\section{ASSOCIATED CONTENT}

\section{Supporting Information}

Experimental section, $\mathrm{CO}_{2}$ adsorption capacity, TGA curves, SEM images, elemental mappings, TEM images, and optimization of the photocatalytic conditions. 


\section{AUTHOR INFORMATION}

\section{Corresponding Author}

eslee@ postech.ac.kr

\section{ORCID}

Eunsung Lee: 0000-0002-1507-098X

Notes

The authors declare no competing financial interest.

\section{ACKNOWLEDGMENT}

This work was financially supported by the National Research Foundation of Korea (NRF-2019R1A2C2010732). C.-X. Liu gratefully acknowledges the Chinese Scholarship Council (CSC) for financial support.

\section{REFERENCES}

(1) (a) Wan, S.; Guo, J.; Kim, J.; Ihee, H.; Jiang, D., A belt-shaped, blue luminescent, and semiconducting covalent organic framework. Angew. Chem., Int. Ed. 2008, 47, 8826-8830. (b) Joshi, T.; Chen, C.; Li, H.; Diercks, C. S.; Wang, G.; Waller, P. J.; Li, H.; Bredas, J. L.; Yaghi, O. M.; Crommie, M. F., Local Electronic Structure of Molecular Heterojunctions in a Single-Layer 2D Covalent Organic Framework. Adv. Mater. 2019, 31, 1805941. (c) Geng, K.; He, T.; Liu, R.; Dalapati, S.; Tan, K. T.; Li, Z.; Tao, S.; Gong, Y.; Jiang, Q.; Jiang, D., Covalent Organic Frameworks: Design, Synthesis, and Functions. Chem. Rev. 2020, 120, 8814-8933. (d) Leith, G. A.; Martin, C. R.; Mayers, J. M.; Kittikhunnatham, P.; Larsen, R. W.; Shustova, N. B., Confinementguided photophysics in MOFs, COFs, and cages. Chem. Soc. Rev. 2021, $50,4382-4410$.

(2) (a) Ding, S. Y.; Wang, W., Covalent organic frameworks (COFs): from design to applications. Chem. Soc. Rev. 2013, 42, 548-568. (b) Li, Y.; Guo, L.; Lv, Y.; Zhao, Z.; Ma, Y.; Chen, W.; Xing, G.; Jiang, D.; Chen, L., Polymorphism of 2D Imine Covalent Organic Frameworks. Angew. Chem., Int. Ed. 2021, 60, 5363-5369. (c) Jin, E.; Li, J.; Geng, K.; Jiang, Q.; Xu, H.; Xu, Q.; Jiang, D., Designed synthesis of stable light-emitting two-dimensional sp2 carbon-conjugated covalent organic frameworks. Nat. Commun. 2018, 9, 4143. (d) Wang, G. B.; Zhu, F. C.; Lin, Q. Q.; Kan, J. L.; Xie, K. H.; Li, S.; Geng, Y.; Dong, Y. B., Rational design of benzodifuran-functionalized donor-acceptor covalent organic frameworks for photocatalytic hydrogen evolution from water. Chem. Commun. 2021, 57, 4464-4467.

(3) (a) Chen, X.; Geng, K.; Liu, R.; Tan, K. T.; Gong, Y.; Li, Z.; Tao, S.; Jiang, Q.; Jiang, D., Covalent Organic Frameworks: Chemical Approaches to Designer Structures and Built-In Functions. Angew. Chem., Int. Ed. 2020, 59, 5050-5091. (b) Wang, G.-B.; Li, S.; Yan, C.X.; Zhu, F.-C.; Lin, Q.-Q.; Xie, K.-H.; Geng, Y.; Dong, Y.-B., Covalent organic frameworks: emerging high-performance platforms for efficient photocatalytic applications. J. Mater. Chem. A. 2020, 8, 69576983. (c) Thomas, S.; Li, H.; Dasari, R. R.; Evans, A. M.; Castano, I.; Allen, T. G.; Reid, O. G.; Rumbles, G.; Dichtel, W. R.; Gianneschi, N. C.; Marder, S. R.; Coropceanu, V.; Brédas, J.-L., Design and synthesis of two-dimensional covalent organic frameworks with four-arm cores: prediction of remarkable ambipolar charge-transport properties. Mater. Horizons. 2019, 6, 1868-1876. (d) Wei, P. F.; Qi, M. Z.; Wang, Z. P.; Ding, S. Y.; Yu, W.; Liu, Q.; Wang, L. K.; Wang, H. Z.; An, W. K.; Wang, W., Benzoxazole-Linked Ultrastable Covalent Organic Frameworks for Photocatalysis. J. Am. Chem. Soc. 2018, 140, 46234631.

(4) (a) Keller, N.; Bein, T., Optoelectronic processes in covalent organic frameworks. Chem. Soc. Rev. 2021, 50. 1813-1845. (b) He, T.; Geng, K.; Jiang, D., Engineering Covalent Organic Frameworks for Light-Driven Hydrogen Production from Water. ACS Mater. Lett. 2019, $1,203-208$.
(5) DeBlase, C. R.; Silberstein, K. E.; Truong, T. T.; Abruna, H. D.; Dichtel, W. R., beta-Ketoenamine-linked covalent organic frameworks capable of pseudocapacitive energy storage. J. Am. Chem. Soc. 2013, 135, 16821-16824.

(6) Pachfule, P.; Acharjya, A.; Roeser, J.; Langenhahn, T.; Schwarze, M.; Schomacker, R.; Thomas, A.; Schmidt, J., Diacetylene Functionalized Covalent Organic Framework (COF) for Photocatalytic Hydrogen Generation. J. Am. Chem. Soc. 2018, 140, 1423-1427.

(7) (a) Kuhn, P.; Antonietti, M.; Thomas, A., Porous, covalent triazinebased frameworks prepared by ionothermal synthesis. Angew. Chem., Int. Ed. 2008, 47, 3450-3453. (b) Dai, C.; He, T.; Zhong, L.; Liu, X.; Zhen, W.; Xue, C.; Li, S.; Jiang, D.; Liu, B., 2,4,6-Triphenyl-1,3,5Triazine Based Covalent Organic Frameworks for Photoelectrochemical $\mathrm{H}_{2}$ Evolution. Adv. Mater. Interfaces. 2021, 8, 2002191. (c) Wang, Y.; Hao, W.; Liu, H.; Chen, R.; Pan, Q.; Li, Z.; Zhao, Y., Facile construction of fully $\mathrm{sp}(2)$-carbon conjugated twodimensional covalent organic frameworks containing benzobisthiazole units. Nat.Commun. 2022, 13, 100.

(8) (a) Kewei Wang, L.-M. Y., Xi Wang, Liping Guo, Guang Cheng, Chun Zhang, Shangbin Jin, Bien Tan, and Andrew Cooper, Covalent Triazine Frameworks via a Low-Temperature Polycondensation Approach. Angew. Chem. Int. Ed. 2017, 56, 14149 -14153. (b) Kulkarni, R.; Noda, Y.; Kumar Barange, D.; Kochergin, Y. S.; Lyu, P.; Balcarova, B.; Nachtigall, P.; Bojdys, M. J., Real-time optical and electronic sensing with a beta-amino enone linked, triazine-containing 2D covalent organic framework. Nat. Commun. 2019, 10, 3228. (c) Li, Y.; Han, Y.; Chen, M.; Feng, Y.; Zhang, B., Construction of a flexible covalent organic framework based on triazine units with interesting photoluminescent properties for sensitive and selective detection of picric acid. $R S C A d v .2019,9,30937-30942$.

(9) (a) Lyu, H.; Diercks, C. S.; Zhu, C.; Yaghi, O. M., Porous Crystalline Olefin-Linked Covalent Organic Frameworks. J. Am. Chem. Soc. 2019, 141, 6848-6852. (b) Xu, J.; He, Y.; Bi, S.; Wang, M.; Yang, P.; Wu, D.; Wang, J.; Zhang, F., An Olefin-Linked Covalent Organic Framework as a Flexible Thin-Film Electrode for a High-Performance Micro-Supercapacitor. Angew. Chem. Int. Ed. 2019, 58, 12065-12069. (10) (a) Wei, S.; Zhang, F.; Zhang, W.; Qiang, P.; Yu, K.; Fu, X.; Wu, D.; Bi, S.; Zhang, F., Semiconducting 2D Triazine-Cored Covalent Organic Frameworks with Unsubstituted Olefin Linkages. J. Am. Chem. Soc. 2019, 141, 14272-14279. (b) Wang, Z.; Yang, Y.; Zhao, Z.; Zhang, P.; Zhang, Y.; Liu, J.; Ma, S.; Cheng, P.; Chen, Y.; Zhang, Z., Green synthesis of olefin-linked covalent organic frameworks for hydrogen fuel cell applications. Nat. Commun. 2021, 12, 1982.

(11) (a) Liu, R.; Tan, K. T.; Gong, Y.; Chen, Y.; Li, Z.; Xie, S.; He, T.; Lu, Z.; Yang, H.; Jiang, D., Covalent organic frameworks: an ideal platform for designing ordered materials and advanced applications.Chem. Soc. Rev. 2021, 50, 120-242. (b) Zhang, F.; Hao, H.; Dong, X.; Li, X.; Lang, X., Olefin-linked covalent organic framework nanotubes based on triazine for selective oxidation of sulfides with $\mathrm{O} 2$ powered by blue light. Appl. Catal. B. 2022, 305, 121027. (c) Evans, A. M.; Ryder, M. R.; Ji, W.; Strauss, M. J.; Corcos, A. R.; Vitaku, E.; Flanders, N. C.; Bisbey, R. P.; Dichtel, W. R., Trends in the thermal stability of two-dimensional covalent organic frameworks. Faraday Discuss. 2021, 225, 226-240.

(12) Barman, S.; Singh, A.; Rahimi, F. A.; Maji, T. K., Metal-Free Catalysis: A Redox-Active Donor-Acceptor Conjugated Microporous Polymer for Selective Visible-Light-Driven $\mathrm{CO}_{2}$ Reduction to $\mathrm{CH}_{4}$. J. Am. Chem. Soc. 2021, 14, 16284-16292.

(13) Liu, L.; Gao, M. Y.; Yang, H.; Wang, X.; Li, X.; Cooper, A. I., Linear Conjugated Polymers for Solar-Driven Hydrogen Peroxide Production: The Importance of Catalyst Stability. J. Am. Chem. Soc. 2021, 143, 19287-19293.

(14) (a) Zhang, T.; Xing, G.; Chen, W.; Chen, L., Porous organic polymers: a promising platform for efficient photocatalysis. Mater. Chem. Front. 2020, 4, 332-353. (b) Wang, H.; Wang, H.; Wang, Z.; Tang, L.; Zeng, G.; Xu, P.; Chen, M.; Xiong, T.; Zhou, C.; Li, X.; Huang, D.; Zhu, Y.; Wang, Z.; Tang, J., Covalent organic framework photocatalysts: structures and applications. Chem. Soc. Rev. 2020, 49, 4135-4165. (c) Sharma, R. K.; Yadav, P.; Yadav, M.; Gupta, R.; Rana, P.; Srivastava, A.; Zbořil, R.; Varma, R. S.; Antonietti, M.; Gawande, 
M. B., Recent development of covalent organic frameworks (COFs): synthesis and catalytic (organic-electro-photo) applications. Mater Horizons. 2020, 7, 411-454.

(15) (a) Wang, T.-X.; Liang, H.-P.; Anito, D. A.; Ding, X.; Han, B.-H., Emerging applications of porous organic polymers in visible-light photocatalysis. J. Mater. Chem. A. 2020, 8, 7003-7034. (b) Zhi, Y.; Wang, Z.; Zhang, H. L.; Zhang, Q., Recent Progress in Metal-Free Covalent Organic Frameworks as Heterogeneous Catalysts. Small.2020, 16, e2001070.

(16) (a) Hu, X.-L.; Li, H.-G.; Tan, B.-E., COFs-based Porous Materials for Photocatalytic Applications. Chinese J. Polym.Sci. 2020, 38, 673 684. (b) Q, Yang.; Luo, M-L.; Kewei Liu.; H-M, Cao.; H-J, Yan.; Covalent organic frameworks for photocatalytic applications, Appl. Catal. B. 2020, 276, 119174. (c) Zhao, J.; Ren, J.; Zhang, G.; Zhao, Z.; Liu, S.; Zhang, W.; Chen, L., Chem. Eur. J. 2021, 27, 10781-10797.

(17) Sonalin, S.; Kurlekar, K.; Anjali, A.; Imran, P. M.; Nagarajan, S., Synthesis of Phenanthro[9,10- d]imidazoles and their Potential Applications in Solution Processable Bottom-Gated OFETs. Asian J. Org. Chem. 2020, 9, 939-946.

(18) Chen, S.; Wu, Y.; Zhao, Y.; Fang, D., Deep blue organic lightemitting devices enabled by bipolar phenanthro[9,10-d]imidazole derivatives. $R S C A d v$. 2015, 5, 72009-72018.

(19) Tagare, J.; Vaidyanathan, S. Recent development of phenanthroimidazole-based fluorophores for blue organic lightemitting diodes (OLEDs): an overview. J. Mater. Chem. C. 2018, 6, 10138-10173.

(20)Yu, Y.; Zhao, R.; Liu, H.; Zhang, S.; Zhou, C.; Gao, Y.; Li, W.; Yang, B., Highly efficient deep-blue light-emitting material based on V-Shaped donor-acceptor triphenylamine-phenanthro[9,10d]imidazole molecule. Dyes. Pigments. 2020, 180, 108511-108518.

(21)Kula, S.; Ledwon, P.; Maroń, A. M.; Siwy, M.; Grzelak, J.; Szalkowski, M.; Maćkowski, S.; Schab-Balcerzak, E., Synthesis, photophysical properties and electroluminescence characterization of 1-phenyl-1H-phenanthro[9,10-d]imidazole derivatives with $\mathrm{N}$-donor substituents. Dyes. Pigments. 2021, 192, 109437-109446.

(22) Idris, M.; Coburn, C.; Fleetham, T.; Milam-Guerrero, J.; Djurovich, P. I.; Forrest, S. R.; Thompson, M. E., Phenanthro[9,10 d]triazole and imidazole derivatives: high triplet energy host materials for blue phosphorescent organic light emitting devices. Mater. Horizons. 2019, 6, 1179-1186.

(23) Kaleeswaran, D.; Vishnoi, P.; Murugavel, R., [3+3] Imine and $\beta$ ketoenamine tethered fluorescent covalent-organic frameworks for CO2 uptake and nitroaromatic sensing. J. Mater. Chem. C. 2015, 3, 7159-7171.

(24) El-Mahdy, A. F. M.; Hung, Y.-H.; Mansoure, T. H.; Yu, H.-H.; Hsu, Y.-S.; Wu, K. C. W.; Kuo, S.-W., Synthesis of $[3+3] \beta-$ ketoenamine-tethered covalent organic frameworks (COFs) for highperformance supercapacitance and $\mathrm{CO} 2$ storage. J. Taiwan. Inst. Chem. E. 2019, 103, 199-208.

(25) Peng, L.; Chang, S.; Liu, Z.; Fu, Y.; Ma, R.; Lu, X.; Zhang, F.; Zhu, W.; Kong, L.; Fan, M., Visible-light-driven photocatalytic CO2 reduction over ketoenamine-based covalent organic frameworks: role of the host functional groups. Catal. Sci. Technol. 2021, 11, 1717-1724. (26) Daugherty, M. C.; Vitaku, E.; Li, R. L.; Evans, A. M.; Chavez, A. D.; Dichtel, W. R., Improved synthesis of beta-ketoenamine-linked covalent organic frameworks via monomer exchange reactions. Chem. Commun. 2019, 55, 2680-2683.

(27) Lin, C.; Liu, X.; Yu, B.; Han, C.; Gong, L.; Wang, C.; Gao, Y.; Bian, Y.; Jiang, J., Rational Modification of Two-Dimensional DonorAcceptor Covalent Organic Frameworks for Enhanced Visible Light Photocatalytic Activity. ACS Appl. Mater. Inter. 2021, 13, 2704127048. 


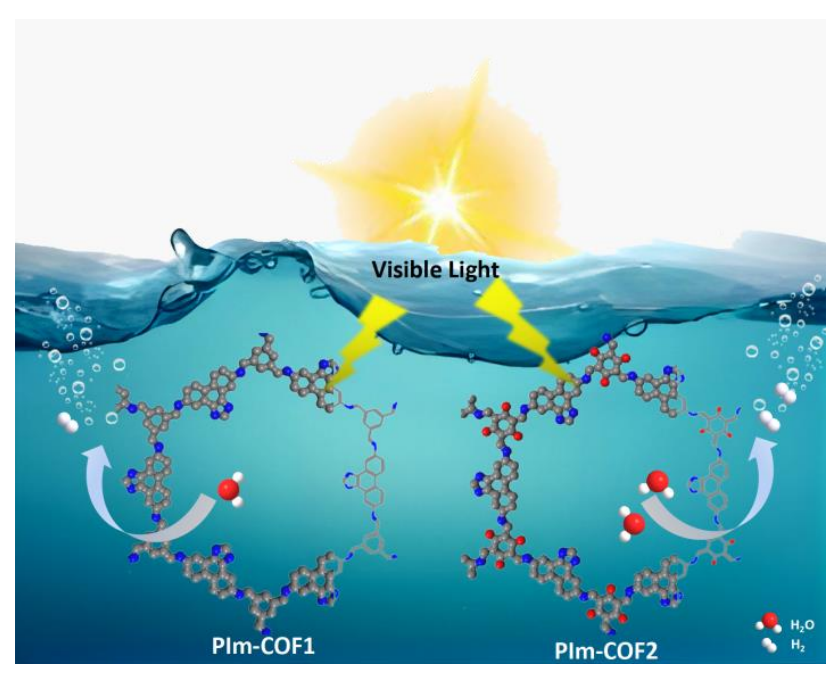

